\title{
Treatment of HIV-Associated Nephropathies
}

\author{
Usama Elewa $^{a}$ Ana Maria Sandri ${ }^{b}$ Stacey A. Rizzac Fernando C. Fervenza ${ }^{d}$ \\ ${ }^{a}$ New Kasr Al-Aini Teaching Hospital, Cairo University, Cairo, Egypt; ${ }^{b}$ Division of Infectious Diseases, Hospital São \\ Lucas da PUCRS, Porto Alegre, Brazil; Divisions of ${ }^{\mathrm{C}}$ Infectious and Diseases and ${ }^{\mathrm{d}}$ Nephrology and Hypertension, \\ Mayo Clinic, Rochester, Minn., USA
}

\section{Key Words}

Human immunodeficiency virus · Nephropathy · Therapy

\begin{abstract}
In patients with HIV, the use of highly active antiretroviral therapy has improved life expectancy. At the same time, this increase in life expectancy has been associated with a higher frequency of chronic kidney disease due to factors other than HIV infection. Besides HIV-associated nephropathy, a number of different types of immune complex and non-immune complex-mediated processes have been identified on kidney biopsies, including vascular disease (nephrosclerosis), diabetes, and drug-related renal injury. In this setting, renal biopsy needs to be considered in order to obtain the correct diagnosis in individual patients with HIV and kidney impairment. Many issues regarding the optimal treatment of the different pathological processes affecting the kidneys of these patients have remained unresolved. Further research is needed in order to optimize treatment and renal outcomes in patients with HIV and kidney disease.
\end{abstract}

Copyright $\odot 2011$ S. Karger AG, Basel

\section{Introduction}

Approximately 2.7 million people a year are infected with HIV worldwide [1]. In the USA, there are about 1 million infected people, and although the number of new cases of acquired immunodeficiency syndrome (AIDS) reported each year has been stable, at approximately 40,000 , the incidence of HIV infection and other sexually transmitted infections has increased in certain atrisk populations, such as men who have sex with men. At the same time, blacks, Hispanics, and women are disproportionately represented among persons with HIV infection, AIDS, or both [2]. Kidney disease is a relatively frequent complication of patients infected with HIV. Human immunodeficiency virus-associated nephropathy (HIVAN), defined on renal biopsy as collapsing focal glomerulosclerosis, is the most common cause of chronic kidney disease (CKD) in patients with HIV and overwhelmingly affects patients of African descent $[3,4]$. Biopsy-proven HIVAN has been reported in $>80 \%$ of 30 patients with HIV screened for proteinuria in South Africa [5] and in 53-79\% of HIV-infected patients of African descent in studies from the USA and Europe [6-9]. In African-Americans, HIVAN is associated with younger age and lower estimated glomerular filtration rate (eGFR) [10]. In this last study, nephrotic-range protein-

Fernando C. Fervenza, MD, PhD

Division of Nephrology and Hypertension

Mayo Clinic College of Medicine

200 First Street, SW, Rochester, MN 55901 (USA)

Tel. +1 507266 7083, E-Mail fervenza.fernando@mayo.edu 
uria predicted HIVAN in $67 \%$ of cases, while a CD4+ count $<200$ cells $/ \mu l$ had a sensitivity and specificity for HIVAN of 74 and $67 \%$, respectively, with positive and negative predictive values of 58 and $82 \%$, respectively [10]. Untreated, HIVAN rapidly progresses to end-stage renal disease (ESRD).

In addition to HIVAN, a number of other HIV-associated kidney diseases have been described $[3,6,11]$. Regardless of the specific histologic lesion, it is clear that persons with kidney disease have a greater risk of death and cardiovascular events when compared with a community-based population without CKD [12]. The same is true for patients with HIV and CKD, where the presence of proteinuria and/or decreased kidney function is associated with increased mortality and worse outcomes [13]. However, little is known regarding the prevalence of proteinuria in HIV patients and the effects of highly active antiretroviral therapy (HAART) on proteinuria.

As will be discussed below, the limitations in the available data highlight the need for good quality prospective controlled studies to address the effects of interventions for treating patients with HIVAN and other HIV-associated glomerular diseases. Although placebo-controlled trials are not ethically appropriate given the strong evidence that HIV-associated end-organ disease is improved with HIV viral control, long-term follow-up is needed to determine if kidney damage in susceptible individuals correlates with the level of viral replication, or immunologic response after treatment with HAART, particularly when control of viremia is incomplete or intermittent. Further evaluation of the effects of angiotensin II blockade (ACE inhibitors, angiotensin II receptor blockers, or renin inhibitors), both in terms of kidney function and proteinuria effects in patients with HIVAN and other HIV-mediated kidney diseases, is required. There is also a need for further delineation regarding the role of immunosuppressive agents commonly used in HIV-negative patients with parenchymal diseases (e.g. corticosteroids), either alone or in combination with HAART in the treatment of HIV-associated kidney diseases. These points have been highlighted in an excellent recent review [14].

\section{HIV-Infected Patients with Kidney Disease other than HIVAN}

Conditions other than HIVAN can affect the kidney in patients with HIV including membranoproliferative glomerulonephritis (including hepatitis C-associated),
Table 1. Spectrum of kidney disease in HIV-infected patients

Glomerular diseases

HIVAN-collapsing FSGS

Non-collapsing FSGS

Membranoproliferative glomerulonephritis (hepatitis C and cryoglobulinemia)

Lupus-like glomerulonephritis

Membranous nephropathy (hepatitis B)

IgA nephropathy

Post-infectious glomerulonephritis

Diabetic nephropathy

Minimal change nephropathy

Amyloidosis

Nephrosclerosis

Thrombotic microangiopathies

Fibrillary glomerulonephritis

ANCA-associated vasculitis and anti-GBM disease (rare)

Interstitial diseases

Acute or chronic interstitial nephritis

Lymphoma

Acute tubular necrosis

Pyelonephritis

Medication-related

Crystal nephropathy: indinavir, nelfinavir, atazanavir, intravenous acyclovir, sulfadiazine

Proximal tubulopathy (Fanconi syndrome): tenofovir, lamivudine, abacavir

Didanosine

Distal tubulopathy: amphotericin B

lupus-like glomerulonephritis, IgA nephropathy, membranous nephropathy, diabetic nephropathy, thrombotic microangiopathies, amyloidosis, hypertension, and medication-associated renal toxicity $[6,11,15]$ (table 1 ). Szczech et al. [6] reported on a cohort study that included all HIV-infected patients who underwent renal biopsy during the course of their clinical care at 6 major medical centers in the USA. Of the 89 patients who were included in the study, renal biopsy showed HIVAN in 42 cases, but lesions other than HIVAN were seen in 47 cases and included immune complex glomerulonephritis, membranous nephropathy, membranoproliferative glomerulonephritis, IgA nephropathy, diabetic nephropathy, and hypertensive nephrosclerosis, among other lesions [6]. Similarly, Haas et al. [16] showed that $40 \%$ of patients infected with HIV and nephropathy had HIVAN, but $34 \%$ had other pathological processes including diffuse proliferative glomerulonephritis, focal proliferative glomerulonephritis, membranous nephropathy and lupus-like glomerulonephritis. In patients with HIV infection, 
many of these pathologies can mimic HIVAN, but the therapeutical approach is likely to differ among the different pathological processes $[3,6,11,17]$.

Based on the information presented above, Cohen and Kimmel [18] recently reviewed the rational for a kidney biopsy in the diagnosis of HIV-associated kidney disease. These authors point out that the spectrum of nephropathies in patients with HIV infection varies widely with geographic setting and ethnicity [3]. Studies in HIV-infected patients with kidney disease from Africa showed a high prevalence of HIVAN, but other forms of glomerulonephritis and interstitial nephritis were also present [5]. Similarly, Gernholtz et al. [19] found that 21 of 99 black South African HIV patients with HIV and kidney involvement had an immune complex-mediated disease.

It has also been recognized that with prolonged survival and aging of the HIV-infected population, the spectrum of kidney disease in patients with HIV is now reflecting the growing burden of other comorbidities such as diabetes and hypertension $[6,20]$. Wyatt et al. [21] recently reported on the variety of kidney pathologies found in a prospective cohort of HIV patients (the Manhattan HIV Brain Bank) who had consented to postmortem organ donation. Nearly one third of 89 kidney tissue donors had CKD, and in 75 cases there was evidence of some renal pathology. The most common diagnoses were arteriolar nephrosclerosis, HIVAN and a number of different glomerulonephritides, as well as pyelonephritis, interstitial nephritis, diabetic nephropathy, fungal infection and amyloidosis.

On the other hand, although antineutrophil cytoplasmic antibodies (ANCA) are frequently found in the sera of HIV-positive patients, with a frequency varying from 18 to $41.0 \%$, no correlation has been found between ANCA positivity and the presence of clinically active vasculitis in these patients [22-24]. In the majority of these cases, immunofluorescence reveals an atypical ANCA pattern. Specific ELISA testing demonstrates binding to a variety of antigens including proteinase-3, myeloperoxidase, lysozyme, lactoferrin, cathepsin G, and human leukocyte elastase, but in the majority of the patients target antigen could not be identified [22]. To date, only 2 cases with HIV who developed an active ANCA-positive vasculitis have been reported $[23,25]$. The rarity of clinical cases of ANCA-associated vasculitis in HIV patients suggests that HIV may in fact lessen the chance of developing active vasculitis [26]. Similarly, there has been only 1 case report on anti-GBM disease in a patient with HIV [27]. The reasons why these vasculitides are rare in patients with HIV are unknown.
The fact that HIVAN is not the only nephropathy associated with HIV infection means a kidney biopsy should be strongly considered when evaluating patients with HIV and kidney disease. On the other hand, does a young African-American patient, who is HIV-positive, has a CD $4+$ count $<200$ cells/ $\mu$ l, high viral load, sudden onset of nephrotic syndrome, declining kidney function, benign urinary sediment, and enlarged echogenic kidneys on renal ultrasound, really need a biopsy to diagnose HIVAN? The studies presented above outline the uncertainties of achieving the correct diagnosis in a patient with HIV and renal involvement without a renal biopsy. We advocate for a liberal use of renal biopsy in patients with HIV and renal involvement, with the understanding that the decision to proceed with a biopsy needs to be taken within the clinical context of each individual patient.

\section{Treatment}

\section{Antiretroviral Therapy}

The primary goal of antiretroviral therapy is to reduce HIV-associated morbidity and mortality. This can be best accomplished by using HAART to maximally inhibit HIV replication, as measured by consistent plasma HIV RNA (viral load) values below the level of detection using commercially available assays. Recently updated guidelines by the Department of Health and Human Services (DHHS) can be accessed at http://www.aidsinfo.nih.gov/ Guidelines/GuidelineDetail.aspx?GuidelineID=7. Ideally, effective antiretroviral therapy should also prevent the development of HIV-associated kidney disease and/ or slow the rate of kidney function loss in patients already compromised while at the same time, decreasing morbidity and mortality in this high-risk population.

Data from uncontrolled or retrospective studies [2833] and from a randomized controlled trial [34] suggest that HAART (defined as combination therapy with 3 or more drugs) is beneficial in both preservation and improvement of kidney function in patients with HIV.

Transient remission of nephrotic syndrome with zidovudine was rapidly followed with progression to ESRD when treatment was stopped [30]. Similarly, Ifudu et al. [31] followed $23 \mathrm{HIV-infected} \mathrm{patients} \mathrm{treated} \mathrm{with} \mathrm{zido-}$ vudine and compared the subgroup compliant with this treatment to those who were non-compliant. At the beginning of the study, 14 patients had proteinuria and 8 had a serum creatinine of $\geq 1.3 \mathrm{gm} / \mathrm{dl}$. The non-compliant patients progressed to ESRD within $8 \pm 2$ weeks. 
Within the compliant group, mean serum creatinine remained stable and no patients required dialysis.

Further evidence that antiretroviral medications may affect the progression of HIVAN comes from a study of 19 biopsy-proven HIVAN cases in which patients who were treated with a protease inhibitor experienced slower decline of kidney function as compared with those not receiving protease inhibitors [33]. Kirchner [32] reported on 3 patients believed to have HIVAN who exhibited marked improvement in kidney function after treatment with a regimen comprising 2 nucleoside reverse transcriptase inhibitors and a protease inhibitor. Similarly, Scheurer [35] reported a case of rapid reversal of ESRD after the initiation of HAART in a person with biopsyproven HIVAN. On the other hand, relapse of HIVAN has been documented following discontinuation of HAART [36]. Finally, Atta et al. [37] reported on an observational study in 26 patients with biopsy-proven HIVAN who had been treated with antiretroviral therapy (defined as initiation of at least 1 antiretroviral agent) and compared it with 10 patients who did not receive antiretroviral therapy and found kidney survival to be significantly better in the treated group (18 vs. 4 months in the untreated group).

In the Strategies for Management of Antiretroviral Therapy (SMART) Group study, a total of 5,472 patients (29\% blacks) infected with HIV who had a CD4+ count $>350$ cells/ $\mu$ l were randomly assigned to the continuous use of antiretroviral therapy (2,752 patients; the viral suppression group) or the episodic use of antiretroviral therapy (2,720 patients; the drug conservation group) and were followed for an average of 16 months before the protocol was modified for the drug conservation group [34]. In this study, renal disease developed in 9 of 2,720 patients ( 0.2 events $/ 100$ person-years) in the drug conservation group versus 2 of 2,752 patients ( 0.1 events $/ 100$ person-years) who were randomized to continuous use of antiretroviral therapy [34].

More recently, Kalayjian et al. [28] showed in an observational, prospective, multicenter cohort study involving 1,776 HIV patients that suppression of plasma viremia with antiretroviral therapy was associated with improvement in GFR in subjects with both CKD stage $\geq 2$ and low baseline CD $4+$ cell counts $(<200$ cells/ $\mu \mathrm{l})$. In this subset of patients, viral suppression was associated with an average increase in GFR of $9.2 \mathrm{ml} / \mathrm{min} / 1.73 \mathrm{~m}^{2}$ from baseline over a median follow-up of 160 weeks. The magnitude of this association increased in subjects who had greater baseline impairment of renal function, and it was independent of race or sex. The extent of viremic control appears to have a strong association with longitudinal changes in kidney function with a decrease in HIV viral load during follow-up associated with improvement in kidney function while an increase in viral load is associated with worsening kidney function [38].

There is also data suggesting that HAART may prevent the development of HIVAN. Among patients with a prior diagnosis of AIDS, HIVAN incidence was significantly reduced from 26.4 per 1,000 person-years in patients not receiving antiretroviral therapy, to 14.4 per 1,000 person-years in patients treated with nucleoside analogue therapy only, and to 6.8, per 1,000 person-years in those treated with HAART [39]. In multivariate analysis, HIVAN risk was reduced $60 \%$ by use of HAART, and no patient developed HIVAN when HAART had been initiated prior to the development of AIDS [39].

On the other hand, limited information is available regarding the incidence of proteinuria in patients with HIV or its relation to antiviral therapy. The AIDS Clinical Trials Group Longitudinal Linked Randomized Trials (ALLRT) is the largest cohort study to date to evaluate correlates of quantitative proteinuria over time. A spot urine protein to creatinine $(\mathrm{P} / \mathrm{Cr})$ ratio of $\geq 0.2$ and $\geq 1.0$ was found in 16 and $3 \%$ of the 2,857 participants, respectively [40]. Factors associated with $\mathrm{P} / \mathrm{Cr} \geq 0.2$ included older age, lower eGFR, female sex, prior use of antiretroviral therapy, high HIV RNA levels, lower CD4+ cell counts, and history of hypertension, diabetes or hepatitis $\mathrm{C}$ co-infection. Black race was associated with $\mathrm{P} / \mathrm{Cr}$ levels $\geq 1$ but not with $\mathrm{P} / \mathrm{Cr}$ levels $\geq 0.2$. There was no overall change in $\mathrm{P} / \mathrm{Cr}$ ratio over time in the cohort as a whole, although a significant reduction in $\mathrm{P} / \mathrm{Cr}$ ratio was seen in the subset of participants who had a $\mathrm{P} / \mathrm{Cr} \geq 1.0$ at baseline. On the other hand, an increase in $\mathrm{P} / \mathrm{Cr}$ ratio was seen in those participants whose initial measurement was $<0.2$. As pointed out by the authors, these results need to be interpreted with caution since they may have been related to changes in diabetes and hypertension control, viral load, or drug nephrotoxicity.

Further suggestions that that HAART may have an antiproteinuric effect in patients with predicted proteinuria $>1 \mathrm{~g} /$ day comes from a study by Gupta et al. [41], who evaluated the effects of HAART on albumin/creatinine ratios (ACR) during the initial 64 weeks of therapy in previously untreated HIV-infected subjects. 68 patients without preexisting diabetes or hypertension were randomized to receive a protease inhibitor-based $(\mathrm{n}=32)$ versus a non-protease inhibitor-based $(\mathrm{n}=36)$ HAART regimen. There was no significant difference in the change in the ACR in the group as a whole. However, 5 
out of 7 patients with ACR $\geq 3.4 \mathrm{mg} / \mathrm{mmol}$ at study entry showed significant improvement in ACR, ranging from 45 to $95 \%$, and in 3 patients albuminuria completely resolved [41]. Additional benefits of antiretroviral therapy include reduction in HIV-associated inflammation and reduction in HIV transmission.

\section{Angiotensin II Blockade}

Angiotensin-converting enzyme inhibitors and angiotensin II receptor blockers are effective antihypertensive agents that can reduce proteinuria and slow progression of renal disease in both diabetic and non-diabetic chronic nephropathy patients, and for these reasons they are indicated in any patient with proteinuria regardless of the cause [42]. Kimmel et al. [43], in a retrospective analysis of 18 patients with biopsy-proven HIVAN, demonstrated that antiretroviral medications (primarily monotherapy with zidovudine) and ACE inhibitors were both independently associated with a longer time to the development of ESRD. Similarly, Burns et al. [44] compared the clinical course of 12 patients with HIVAN who consented to take fosinopril (10 mg p.o. q.d.) to the course of 8 patients who refused treatment. 7 of the 20 patients in the cohort were taking a single nucleoside reverse transcriptase inhibitor (zidovudine, didanosine, or zalcitabine). Of 11 patients with non-nephrotic-range proteinuria, 7 received treatment and 4 did not. Baseline serum creatinine for treated and untreated patients was $1.3 \pm$ 0.24 and $1.0 \pm 0.25 \mathrm{mg} / \mathrm{dl}$, respectively $(\mathrm{p}=0.07)$. At 24 weeks, serum creatinine of treated patients was basically unchanged at $1.5 \pm 0.34 \mathrm{mg} / \mathrm{dl}$ but it had increased to 4.9 $\pm 2.4 \mathrm{mg} / \mathrm{dl}$ in the untreated group. Similarly, baseline proteinuria for the treated group $(1.6 \pm 0.68 \mathrm{~g} /$ day $)$ remained unchanged (1.25 $\pm 0.86 \mathrm{~g} /$ day) but increased from $0.78 \pm 0.39 \mathrm{~g} /$ day at baseline to $8.5 \pm 1.4 \mathrm{~g} /$ day in the untreated group at 24 weeks. Of the 9 patients with nephrotic-range proteinuria, 5 were treated and had a decline in proteinuria from an average of $5.4 \pm 1.6 \mathrm{~g} /$ day at baseline to $2.8 \pm 1.0 \mathrm{~g} /$ day but increased from $5.2 \pm 0.97$ to $10.5 \pm 3.5 \mathrm{~g} /$ day in the untreated group at 12 weeks $(\mathrm{p}=0.008)$. In this subgroup, average baseline creatinine for treated and untreated patients was $1.7 \pm 0.46$ and 1.9 \pm 0.42 , respectively $(\mathrm{p}=0.4)$, and increased to $2.0 \pm 1.0$ and $9.2 \pm 2.0 \mathrm{mg} / \mathrm{dl}$ in the treated versus untreated $\mathrm{pa}-$ tients at 12 weeks $(\mathrm{p}=0.02)$. This study suggests that treatment with ACE inhibitors may stabilize serum creatinine and proteinuria for up to 24 weeks in HIV-infected patients with non-nephrotic-range proteinuria and for up to 12 weeks in patients with nephrotic-range proteinuria when initial serum creatinine is $\leq 2.0 \mathrm{mg} / \mathrm{dl}$.
More recently, in a prospective, non-randomized, single-center study, Wei et al. [45] examined the long-term effects of ACE inhibition on renal survival in a cohort of 44 consecutive patients with biopsy-proven HIVAN, proteinuria and serum creatinine $\leq 2.0 \mathrm{mg} / \mathrm{dl}$. 28 patients received fosinopril, $10 \mathrm{mg} / \mathrm{day}$, and 16 were followed as controls with end-points including ESRD and death. The median kidney survival of treated patients was 479.5 days, with only 1 patient developing ESRD. All untreated controls progressed to ESRD, with a median renal survival of 146.5 days $(p<0.0001)$. There were no significant differences between treatment and control groups in relation to age, exposure to antiretroviral therapy (defined as $\geq 2$ antiviral drugs for $\geq 30$ consecutive days), CD4+ lymphocyte count, initial serum creatinine concentration, or proteinuria. Risk of renal failure was reduced with ACE inhibitors $(R R=0.003, p<0.0001)$. Exposure to antiretroviral therapy did not have a significant impact on the risk of renal failure. Of the ACE inhibitor-treated group, only 4 of 28 patients (14\%) progressed to ESRD over 5 years compared with all of the 17 patients $(100 \%)$ in the control group $(\mathrm{p}<0.001)$.

\section{Corticosteroids}

A number of retrospective, observational or uncontrolled studies conducted before or during the initial phases of HAART reported variable success with the use of corticosteroids in patients with HIV-associated kidney diseases. Laradi et al. [46] reported on 102 patients (97\% blacks and $71.5 \%$ males) with biopsy-proven HIVAN admitted to 18 hospitals in the Paris area from 1984 through 1996. Median patient follow-up was 165 days (range 43493). At the time of renal biopsy, median values of serum creatinine, proteinuria, and CD4+ cell count were 5.6 $\mathrm{mg} / \mathrm{dl}, 6.5 \mathrm{~g} / \mathrm{day}$, and $48.5 \mathrm{cells} / \mu \mathrm{l}$, respectively. $15 \mathrm{pa}-$ tients were given prednisone $(1 \mathrm{mg} / \mathrm{kg}$ for 2-6 weeks) after the diagnosis of HIVAN. Overall patient survival at $0.5,1$, and 3 years was $73 \pm 5,55 \pm 6$, and $38 \pm 7 \%$, respectively. The proportion of patients free of dialysis at $0.5,1$, and 3 years was $73 \pm 5,60 \pm 7$, and $18 \pm 10 \%$, respectively. In this study, the use of prednisone was associated with a $71 \%$ risk reduction in progression to ESRD, although selection bias may limit the validity of the study.

Similarly, Eustace et al. [47] conducted a retrospective cohort study of 21 patients diagnosed with biopsy-proven HIVAN and progressive renal failure between 1994 and 1997. 13 patients received prednisone, $60 \mathrm{mg} /$ day for 1 month, followed by a several-month taper, whereas 8 patients did not. Mean baseline serum creatinine was 6.2 
and $6.8 \mathrm{mg} / \mathrm{dl}$, respectively ( $\mathrm{p}>0.05$ ). After 3 months, kidney failure developed in 6 of the 8 patients who received no treatment and 3 progressed to ESRD. Of the 13 patients treated with prednisone, only 2 developed kidney failure, but none progressed to ESRD. In the corticosteroid-treated group, proteinuria decreased by $5.5 \mathrm{~g} /$ day $(\mathrm{p}=0.01)$. Improvement remained significant despite adjustment for baseline creatinine, proteinuria, CD4+ count, intravenous drug use, hepatitis B, and hepatitis C. At 6 months, only 1 of the non-corticosteroid-treated patients but 7 of the corticosteroid-treated group continued to have independent renal function $(\mathrm{p}=0.06)$. Three of the corticosteroid-treated group continued to have independent function at 2 years of follow-up. There was no significant difference in the incidence of hospitalizations or of serious infections between the 2 groups.

Corticosteroids were also used by Smith et al. [48] who prospectively treated 20 consecutive patients with biopsyproven HIVAN $(n=17)$ or clinical characteristics of HIVAN $(\mathrm{n}=3)$ and serum creatinine $>2 \mathrm{mg} / \mathrm{dl}$ or proteinuria $>2.0 \mathrm{~g} /$ day or both with prednisone at a dose of 60 $\mathrm{mg} /$ day for 2-11 weeks, followed by a tapering course of prednisone over a 2- to 26 -week period. 19 patients had serum creatinine concentrations $>2 \mathrm{mg} / \mathrm{dl}$, and 2 of them progressed to ESRD in 4-5 weeks. In 17 patients, serum creatinine levels decreased from $8.1 \pm 1.1 \mathrm{mg} / \mathrm{dl}$ (mean $\pm \mathrm{SE})$ to $3.0 \pm 0.4 \mathrm{mg} / \mathrm{dl}(\mathrm{p}<0.001) .5$ patients relapsed after prednisone was discontinued and were retreated. In these 5 patients, serum creatinine decreased from $8.2 \pm$ 1.2 to $3.9 \pm 0.5 \mathrm{mg} / \mathrm{dl}(\mathrm{p}<0.01)$ in response to the second course of prednisone. In 12 of 13 patients in whom proteinuria was quantified, there was a reduction from $9.1 \pm$ 1.8 to $3.2 \pm 0.6 \mathrm{~g} /$ day $(\mathrm{p}<0.005)$. The 20 patients have been followed for a median of 44 weeks (range 8-107). 8 patients reached ESRD. 11 died from complications of HIV disease 14-107 weeks after institution of prednisone; none were receiving prednisone at the time of death. 7 were alive and free from ESRD at a median of 25 weeks (range 8-81) from the initiation of prednisone therapy. 6 patients developed a total of 7 serious infections while receiving prednisone, including Mycobacterium aviumcomplex infection in 2 and CMV retinitis in 3 patients. The authors concluded that prednisone improves serum creatinine and proteinuria in a substantial proportion of adults with HIVAN.

In the study by Eustace et al. [47], prednisone was not associated with increased risk of infection. However, the use of high-dose corticosteroids in HIV patients was associated with a high risk of avascular necrosis of the femoral head $[49,50]$. In the era of modern HAART therapy, it is unclear what the potential benefits are, if any, of the use of corticosteroids in the treatment of patients with HIVAN, or other HIV-related kidney diseases. Data presented in an abstract form suggested that the use of prednisone in combination with HAART is more effective in prolonging renal survival when compared with patients receiving HAART alone or those receiving neither prednisone nor HAART, but no formal publication ever came from this study, and thus the information needs to be viewed with caution [51].

\section{Cyclosporine}

There is only 1 study using cyclosporine in 15 children with HIV and nephrotic syndrome [52]. Mean age at onset of nephrotic syndrome was $4.9 \pm 2.6$ years. 14 patients were black and 1 was Hispanic. $73 \%$ of the patients were female. Kidney biopsy was performed in $80 \%$ of the patients, and demonstrated mesangial hypercellularity $(n=5)$, focal segmental glomerulosclerosis $(n=4)$, minimal change disease $(n=2)$, and $\operatorname{IgM}$ nephropathy $(n=1)$. Deposition of 1 or more immunoglobulins was noted in all but 1 patient in which renal biopsy immunofluorescence was available. Corresponding electron-dense deposits were seen by electron microscopy in $78 \%$ of specimens. Prednisone did not induce a remission of nephrotic syndrome in the 13 patients treated, whereas cyclosporine did so in the 3 patients to whom it was administered. One child in whom cyclosporine was discontinued had a proteinuria relapse.

\section{Limitations}

Despite the recommendation to start HAART therapy in all patients with HIVAN, the effect of this intervention needs further evaluation. A recent search involving the Cochrane Central Register of Controlled Trials (CENTRAL), the Cochrane Renal Group's specialized register, Medline, Embase, AIDSearch, reference lists of articles and conference proceedings without language restrictions, international clinical trials registry platform search portal, and pharmaceutical companies that manufacture the drugs used for interventions, found no RCT-based evidence upon which to base guidelines for the treatment of HIVAN [53]. There is also hardly any evidence to suggest that HAART may be of benefit in patients with HIVassociated immune complex-mediated renal diseases and thrombotic microangiopathies $[3,11,18]$. In a series of 89 patients who underwent kidney biopsy, the beneficial response to antiretroviral therapy and kidney function ob- 
served in patients with HIVAN was not seen among those with glomerular diseases other than HIVAN [6]. It is also unlikely that HAART would improve kidney outcomes in HIV patients co-infected with $\mathrm{HBV}$ or $\mathrm{HCV}$, and whose kidney disease is related to these infections, without specific therapy for the coexisting viral disease. Furthermore, a recent study involving 26,569 patients with HIV who received care at 7 leading HIV centers in the United Kingdom described the clinical epidemiology of HIV-associated ESRD from 1998 to 2007. 68 patients (0.31\%) had developed ESRD secondary to HIV-mediated renal disease. A total of 44 patients (64.7\%) were black. The most common renal diagnosis was HIVAN which was present in 36 (52.9\%) of all patients and $81.8 \%$ of black patients. Although lower CD4+ cell counts was significantly associated with the development of ESRD in analysis restricted to black patients, no association was found between viral load or current HAART status and development of ESRD in this population [54]. A number of different pathologies affected the kidney of non-black patients, but also in this group it was unclear whether HAART prevented or delayed progression to ESRD [54]. The authors concluded that whereas overall patient survival suggested an important benefit of HAART, no additional kidney benefit of early initiation of HAART or viral suppression could be demonstrated in this large cohort of patients with established HIVAN. Severity of chronic kidney damage, as quantified by biopsy, was the strongest predictor of renal outcome [54].

HAART itself can be associated with acute kidney injury and progressive nephropathy $[3,4,55-58]$. Some patients with normal kidney function at baseline still progress to CKD stage $\geq 3$ despite HAART, as documented in 1.9 and $1.6 \%$ of the patients participating in ALLRT and DART studies, respectively $[28,59]$. Thus, a kidney biopsy should also be considered in patients on HAART who develop signs of acute kidney injury, those who show progressive kidney failure during therapy, and in those in whom other potentially nephrotoxic drugs (besides those in a HAART regimen) are being used, and whose kidney function fails to improved upon discontinuation of the nephrotoxic agent [17].

Although studies suggest that ACE inhibitors used in combination with antiretroviral therapy may slow or stabilize progression of HIVAN if initiated prior to the development of severe kidney failure, no such information is available in patients with HIV-mediated kidney disease other than HIVAN. It should also be remembered that much of the information on the use of ACE inhibitors and corticosteroids in patients with HIV-mediated kidney disease comes from studies completed prior to modern HAART, and little is known regarding their effects on kidney function in the context of modern HAART [14].

\section{Conclusion}

Patients with HIV can be affected by a variety of kidney pathologies that frequently progress to CKD. Antiretroviral therapy has substantially improved the survival of patients with HIV as well as modified the natural course of HIVAN, but its effects on other HIV-mediated renal diseases remain unproven. Antiretroviral therapy should be initiated in all patients with a history of an AIDS-defining illness or with CD4+ count $<350$ cells/ $\mu \mathrm{l}$, and regardless of CD4+ count, in patients with HIVAN. Improved patient survival, however, has resulted in a higher prevalence of CKD in patients with HIV, and a higher risk for progression to ESRD. A renal biopsy should be considered in patients with HIV and kidney involvement in which the cause is not obvious. Standard antiproteinuric therapy, e.g. ACE inhibitors, should be used in all proteinuric HIV patients as tolerated. Further research is needed to delineate the role of HAART, corticosteroids, cyclosporine, and other immunosuppressive agents in the treatment of HIVAN as well as other HIVassociated kidney diseases.

\section{References}

1 UNAIDS: Report on the Global HIV/AIDS Epidemic 2008: Executive Summary. Mexico City, UNAIDS, 2008

2 Sepkowitz KA: One disease, two epidemics - AIDS at 25. N Engl J Med 2006;354: 2411-2414.

3 Kimmel PL, Barisoni L, Kopp JB: Pathogenesis and treatment of HIV-associated renal diseases: lessons from clinical and animal studies, molecular pathologic correlations, and genetic investigations. Ann Intern Med 2003; 139:214-226.

4 Wyatt CM, Klotman PE: HIV-1 and HIV-associated nephropathy 25 years later. Clin J Am Soc Nephrol 2007;2(suppl 1):S20-S24.

5 Han TM, Naicker S, Ramdial PK, Assounga AG: A cross-sectional study of HIV-seropositive patients with varying degrees of proteinuria in South Africa. Kidney Int 2006;69: 2243-2250.

-6 Szczech LA, Gupta SK, Habash R, Guasch A, et al: The clinical epidemiology and course of the spectrum of renal diseases associated with HIV infection. Kidney Int 2004;66: $1145-1152$. 
7 Nochy D, Glotz D, Dosquet P, Pruna A, et al: Renal disease associated with HIV infection: a multicentric study of 60 patients from Paris hospitals. Nephrol Dial Transplant 1993;8: 11-19.

8 Connolly JO, Weston CE, Hendry BM: HIVassociated renal disease in London hospitals. QJM 1995;88:627-634.

$\checkmark 9$ Winston JA, Klotman ME, Klotman PE: HIV-associated nephropathy is a late, not early, manifestation of HIV-1 infection. Kidney Int 1999;55:1036-1040.

-10 Berliner AR, Fine DM, Lucas GM, Rahman $\mathrm{MH}$, et al: Observations on a cohort of HIVinfected patients undergoing native renal biopsy. Am J Nephrol 2008;28:478-486.

$\checkmark 11$ Cohen SD, Kimmel PL: Immune complex renal disease and human immunodeficiency virus infection. Semin Nephrol 2008;28: 535-544.

-12 Go AS, Chertow GM, Fan D, McCulloch CE, et al: Chronic kidney disease and the risks of death, cardiovascular events, and hospitalization. N Engl J Med 2004;351:1296-1305.

-13 Szczech LA, Hoover DR, Feldman JG, Cohen $\mathrm{MH}$, et al: Association between renal disease and outcomes among HIV-infected women receiving or not receiving antiretroviral therapy. Clin Infect Dis 2004;39:1199-1206.

14 Kalayjian RC: The treatment of HIV-associated nephropathy. Adv Chronic Kidney Dis 2010;17:59-71.

15 Nebuloni M, Tosoni A, Barbiano di Belgiojoso G, Rastaldi MP: HIV infection and chronic kidney disease. Eur Nephrol 2010;4: 19-23.

16 Haas M, Kaul S, Eustace JA: HIV-associated immune complex glomerulonephritis with 'lupus-like' features: a clinicopathologic study of 14 cases. Kidney Int 2005;67:13811390.

- 17 Fine DM, Perazella MA, Lucas GM, Atta MG: Kidney biopsy in HIV: beyond HIV-associated nephropathy. Am J Kidney Dis 2008;51:504-514

18 Cohen SD, Kimmel PL: Renal biopsy is necessary for the diagnosis of HIV-associated renal diseases. Nat Clin Pract Nephrol 2009; 5:22-23.

19 Gerntholtz TE, Goetsch SJ, Katz I: HIV-related nephropathy: a South African perspective. Kidney Int 2006;69:1885-1891.

-20 Wyatt CM, Winston JA, Malvestutto CD, Fishbein DA, et al: Chronic kidney disease in HIV infection: an urban epidemic. AIDS 2007;21:2101-2103.

-21 Wyatt CM, Morgello S, Katz-Malamed R, Wei $C$, et al: The spectrum of kidney disease in patients with AIDS in the era of antiretroviral therapy. Kidney Int 2009;75:428-434.

-22 Cornely OA, Hauschild S, Weise C, Csernok $\mathrm{E}$, et al: Seroprevalence and disease association of antineutrophil cytoplasmic autoantibodies and antigens in HIV infection. Infection 1999;27:92-96.
23 Klaassen RJ, Goldschmeding R, Dolman KM, Vlekke AB, et al: Anti-neutrophil cytoplasmic autoantibodies in patients with symptomatic HIV infection. Clin Exp Immunol 1992;87:24-30.

24 Savige JA, Chang L, Horn S, Crowe SM: Antinuclear, anti-neutrophil cytoplasmic and anti-glomerular basement membrane antibodies in HIV-infected individuals. Autoimmunity $1994 ; 18: 205-211$.

25 Davenport A, Grant PJ: False positive autoantibodies in HIV infection. Nephron 1991; 59:515-516.

26 Calabrese LH: Infection with the human immunodeficiency virus type 1 and vascular inflammatory disease. Clin Exp Rheumatol 2004;22:S87-S93.

27 Monteiro EJ, Caron D, Balda CA, Franco M, et al: Anti-glomerular basement membrane glomerulonephritis in an HIV-positive patient: case report. Braz J Infect Dis 2006;10: 55-58.

28 Kalayjian RC, Franceschini N, Gupta SK, Szczech LA, et al: Suppression of HIV-1 replication by antiretroviral therapy improves renal function in persons with low CD4 cell counts and chronic kidney disease. AIDS 2008;22:481-487.

29 Krawczyk CS, Holmberg SD, Moorman AC, Gardner LI, et al: Factors associated with chronic renal failure in $\mathrm{HIV}$-infected ambulatory patients. AIDS 2004;18:2171-2178.

30 Babut-Gay ML, Echard M, Kleinknecht D, Meyrier A: Zidovudine and nephropathy with human immunodeficiency virus infection. Ann Intern Med 1989;111:856-857.

31 Ifudu O, Rao TK, Tan CC, Fleischman H, et al: Zidovudine is beneficial in human immunodeficiency virus associated nephropathy. Am J Nephrol 1995;15:217-221.

\$2 Kirchner JT: Resolution of renal failure after initiation of HAART: three cases and a discussion of the literature. AIDS Read 2002;12: 103-105, 110-112.

-33 Szczech LA, Edwards LJ, Sanders LL, van der Horst C, et al: Protease inhibitors are associated with a slowed progression of HIV-related renal diseases. Clin Nephrol 2002;57:336341.

34 El-Sadr WM, Lundgren JD, Neaton JD, Gordin F, et al: CD4+ count-guided interruption of antiretroviral treatment. N Engl J Med 2006;355:2283-2296.

35 Scheurer D: Rapid reversal of renal failure after initiation of HAART: a case report. AIDS Read 2004;14:443-447.

36 Scialla JJ, Atta MG, Fine DM: Relapse of HIV-associated nephropathy after discontinuing highly active antiretroviral therapy. AIDS 2007;21:263-264.

37 Atta MG, Gallant JE, Rahman MH, Nagajothi $\mathrm{N}$, et al: Antiretroviral therapy in the treatment of HIV-associated nephropathy. Nephrol Dial Transplant 2006;21:28092813.
38 Longenecker CT, Scherzer R, Bacchetti P, Lewis CE, et al: HIV viremia and changes in kidney function. AIDS 2009;23:1089-1096.

39 Lucas GM, Eustace JA, Sozio S, Mentari EK, et al: Highly active antiretroviral therapy and the incidence of HIV-1-associated nephropathy: a 12-year cohort study. Aids 2004; 18:541-546.

40 Gupta SK, Smurzynski M, Franceschini N, Bosch RJ, et al: The effects of HIV type-1 viral suppression and non-viral factors on quantitative proteinuria in the highly active antiretroviral therapy era. Antivir Ther 2009; 14:543-549.

41 Gupta SK, Parker RA, Robbins GK, Dube MP: The effects of highly active antiretroviral therapy on albuminuria in HIV-infected persons: results from a randomized trial. Nephrol Dial Transplant 2005;20:22372242.

42 Jafar TH, Stark PC, Schmid CH, Landa M, et al: Progression of chronic kidney disease: the role of blood pressure control, proteinuria, and angiotensin-converting enzyme inhibition: a patient-level meta-analysis. Ann Intern Med 2003;139:244-252.

43 Kimmel PL, Mishkin GJ, Umana WO: Captopril and renal survival in patients with human immunodeficiency virus nephropathy. Am J Kidney Dis 1996;28:202-208.

44 Burns GC, Paul SK, Toth IR, Sivak SL: Effect of angiotensin-converting enzyme inhibition in HIV-associated nephropathy. J Am Soc Nephrol 1997;8:1140-1146.

$>45$ Wei A, Burns GC, Williams BA, Mohammed $\mathrm{NB}$, et al: Long-term renal survival in HIVassociated nephropathy with angiotensinconverting enzyme inhibition. Kidney Int 2003;64:1462-1471.

46 Laradi A, Mallet A, Beaufils H, Allouache M, et al: HIV-associated nephropathy: outcome and prognosis factors. Groupe d'Etudes Néphrologiques d'Ile de France. J Am Soc Nephrol 1998;9:2327-2335.

47 Eustace JA, Nuermberger E, Choi M, Scheel PJ Jr, et al: Cohort study of the treatment of severe HIV-associated nephropathy with corticosteroids. Kidney Int 2000;58:12531260

48 Smith MC, Austen JL, Carey JT, Emancipator SN, et al: Prednisone improves renal function and proteinuria in human immunodeficiency virus-associated nephropathy. Am J Med 1996;101:41-48.

49 Glesby MJ, Hoover DR, Vaamonde CM: Osteonecrosis in patients infected with human immunodeficiency virus: a case-control study. J Infect Dis 2001;184:519-523.

50 Miller KD, Masur H, Jones EC, Joe GO, et al: High prevalence of osteonecrosis of the femoral head in HIV-infected adults. Ann Intern Med 2002; 137:17-25.

51 Navarrete JE, Pastan SO: Effect of highly active antiretroviral treatment and prednisone in biopsy-proven HIV-associated nephropathy (abstract). J Am Soc Nephrol 2000;11: 93A. 
-52 Ingulli E, Tejani A, Fikrig S, Nicastri A, et al: Nephrotic syndrome associated with acquired immunodeficiency syndrome in children. J Pediatr 1991;119:710-716.

53 Yahaya I, Uthman AO, Uthman MM: Interventions for HIV-associated nephropathy. CochraneDatabaseSystRev2009:CD007183.

54 Bansi L, Hughes A, Bhagani S, Mackie NE, et al: Clinical epidemiology of HIV-associated end-stage renal failure in the UK. AIDS 2009;23:2517-2521.
55 Fine DM, Perazella MA, Lucas GM, Atta MG: Renal disease in patients with HIV infection: epidemiology, pathogenesis and management. Drugs 2008;68:963-980.

$\checkmark 56$ Hammer SM, Eron JJ Jr, Reiss P, Schooley RT, et al: Antiretroviral treatment of adult HIV infection: 2008 recommendations of the International AIDS Society-USA panel. JAMA 2008;300:555-570.

57 Roling J, Schmid H, Fischereder M, Draenert $\mathrm{R}$, et al: HIV-associated renal diseases and highly active antiretroviral therapy-induced nephropathy. Clin Infect Dis 2006;42:14881495.
58 Cohen SD, Chawla LS, Kimmel PL: Acute kidney injury in patients with human immunodeficiency virus infection. Curr Opin Crit Care 2008;14:647-653.

59 Reid A, Stohr W, Walker AS, Williams IG, et al: Severe renal dysfunction and risk factors associated with renal impairment in HIVinfected adults in Africa initiating antiretroviral therapy. Clin Infect Dis 2008;46:12711281.

\title{
Editorial Comment
}

\author{
Meguid El Nahas, Sheffield
}

The review by Elewa and his colleagues is comprehensive and timely as HIV and associated nephropathy (HIVAN) are undergoing a number of revisions in diagnosis and classification. The review highlights a number of new and important issues including the perceived increased prevalence of CKD in HIV-infected individuals and the association with known predisposing factors such as the black race, CD4 count $<200$ cells $/ \mathrm{mm}^{3}$, HIV RNA levels $>4,000$ copies $/ \mathrm{ml}$, but also new and interesting risk factors such as a family history of CKD and the presence of diabetes mellitus, hypertension or hepatitis $\mathrm{C}$ co-infection. This may reflect the rising number of diagnosed $\mathrm{CKD}$, hypertension and diabetes worldwide including areas endemic for HIV infections such as Sub-Saharan Africa. In emerging countries/regions where HIV prevalence is high, CKD is likely to result from the triple hit of poverty, infections and westernization with increased incidence of hypertension and diabetes. Recent interest is also focusing on the genetic predisposition to HIVAN and FSGS with emphasis on a variation in the myosin heavy chain (MYH)9 locus on chromosome 22; this genotype has been associated with increased risk of FSGS, hypertensive nephrosclerosis and HIVAN in AfricanAmericans. However, although polymorphisms in the MYH9 gene on chromosome 22 are strongly associated with HIVAN, the majority of HIV-infected patients with such genetic predisposition linked to MYH9 genotypes do not appear to develop severe kidney disease. This would suggest that additional environmental or inherited factors may be necessary to initiate human HIVAN [1]. In that respect, recent experimental evidence implicates new intracellular pathways (mTOR) for HIV-1 virus induction of HIVAN, with potential for mTOR inhibitors such as rapamycin to attenuate the renal lesions [2]. The review also reminds the reader of the range of renal histological changes associated with HIV infections; this has prompted some authors to suggest that the histological classification of HIV-associated CKD requires review [3].

Also, as highlighted in the review by Elewa and his colleagues, evidence upon which to base treatment recommendations are weak. It is recommended to start HAART therapy in all patients with HIVAN. However, a recent search involving the Cochrane Central Register of Controlled Trials (CENTRAL) found no RCT-based evidence upon which to base guidelines for the treatment of HIVAN [4]. Clearly, more research is needed to understand HIVAN, its epidemiology, classification and treatment.

\section{References}

Núñez M, Saran AM, Freedman BI: Gene-gene and gene-environment interactions in HIV-associated nephropathy: a focus on the MYH9 nephropathy susceptibility gene. Adv Chronic Kidney Dis 2010;17:44-51.

-2 Kumar D, Konkimalla S, Yadav A, Sataranatarajan K, Kasinath BS, Chander PN, Singhal PC: HIV-associated nephropathy: role of mammalian target of rapamycin pathway. Am J Pathol 2010;177:813-821.

3 Naicker S, Fabian J: Risk factors for the development of chronic kidney disease with HIV/AIDS. Clin Nephrol 2010;74(suppl 1):51-56.

4 Yahaya I, Uthman AO, Uthman MM: Interventions for HIV-associated nephropathy. Cochrane Database Syst Rev 2009:CD007183. 